\title{
Impact of Learning Family Medicine in Community in Preclinical Students of Medical Faculty of University of Riau
}

\author{
Elda Nazriati \\ Departement of Medical Education of Faculty of Medicine \\ of Universitas Riau, \\ Riau, Indonesia \\ eldanazriati@gmail.com \\ Adi Heru Husodo \\ Departement of Family Medicine of Faculty of Medicine of \\ Gadjah Mada University, \\ Yogyakarta, Indonesia \\ adiheruhusodo@gmail.com
}

\author{
Ova Emilia \\ Departement of Medical Education of Faculty of Medicine \\ of Gadjah Mada University, \\ Yogyakarta, Indonesia \\ ovaemilia@gmail.com \\ Tri Nur Kristina \\ Departement of Medical Education of Faculty of Medicine \\ of Diponegoro University, \\ Semarang, Indonesia \\ t_nurkristina@yahoo.com
}

\begin{abstract}
WHO recommends for training students in family settings, but its implementation is still challenging. This study was aimed to evaluate learning in family setting with home visit model. One hundred and ten preclinical students of sixth semester were participated in this study. A post-test only control group design was performed to compare the impact of teaching family medicine using home visit model and a combination of lecture and lab exercises. Outputs were assessed using a questionnaire, communication skill test, written test, and focus group discussions. Data were analyzed qualitatively and quantitatively. Students' satisfaction were higher among students learning through home visits model, The doctor-patient communication skills of family medicine approach showed no significant difference between the two study groups but the qualitative data showed positive impact in communication skills of the home visit groups. The ability to plan management of patients with a family medicine approach among home visits groups was significantly higher, Several themes related to home visits that require attention include the advantages, learning experiences, feasibility and challenges of home visit. Home visit method trains students about patient physician communication as well as explore the aspects of social behavior through the observation of house, family, and environment. It also provides a good understanding of the psychosocial and medical aspects for the treatment of chronic diseases, and increases empathy in students. Home visits improved preclinical students' satisfaction and ability in planning patient management with family medicine approach.
\end{abstract}

Keyword—Home visit; satisfaction; doctor-patient communication

\section{INTRODUCTION}

Primary health care has been the backbone of health services. The declaration of Alma Ata in 1978 stated that
WHO recommended family doctors in each country as major health providers in primary health care [1]. According to national health system of Indonesia, primary health care should implement family medicine approach [2-3].

Educational institutions around the world were challenged to develop the curriculum which was more relevant to the needs of the community. Early in 1963 the WHO recommended that all medical schools provided opportunities for students to practice in the family setting to improve the standard of family health services [1]. Some of the recommendations for the improvement of medical education in South East Asia were the theme of primary health care should be a leading figure in the curriculum, community-based teaching should be introduced early and continued throughout the educational program, as well as clinical education settings must be extended to settings that will give students the opportunity to get the required experience [4].

Home visit has been one method of family medicine learning in community settings. It trained students the patient physician communication as well as explore the aspects of social behavior through the observation of house, family, and environment which was difficult to perform by other learning methods such as lectures, skills training in the skills laboratory, and learning in the hospital. The previous studies suggested that home visit was beneficial to create effective communication and patient education. It also provided a good understanding of the psychosocial and medical aspects for the treatment of chronic diseases, and increases empathy in students [5-7]. National consensus of Massachusetts General Hospital, Harvard Medical School, declared that the house was an excellent place to address comprehensive palliative medicine, provide special enrichment and the opportunity to learn about the experiences of patients and families, and also 
study the influence of culture and environment on health car3 [8].

Home visits services have been changed in a few decades, however home visits was still relevant taught to the students in Indonesian. Besides as the method that was expected to increase student understanding of family medicine, Indonesia Health Profile showed an increase in life expectancy and the increasing prevalence of chronic and degenerative disease which gives the potential for increasing demand of home visits. Home visit as the specific learning program has been conducted in the preclinical students in several medical schools in Indonesia, but the implementation programs are widely vary and rarely devoted to learning family medicine.. A home visit model should be designed as the family medicine learning method for preclinical students.

\section{MATERIALS AND METHODS}

The research was conducted in two stages, the first stage was preceded by designing a home visit model, followed by a second phase to assess the impact of learning method of family medicine. The first phase was conducted by qualitative research through literature studies, expert interview, focus group discussion, and pilot study. The second stage was performed by experimental studies using mixed methods, which combines both quantitative and qualitative approaches.

The study used the posttest only control group design to compare the positive impact of learning methods of family medicine in both groups using home visits and the combination of lectures and communication exercises in the skills laboratory. The research samples were collected by stratified random sampling by the last grade point average (GPA), which were grouped into good, moderate, and low. Furthermore, they were randomized by random permutted block into the control and the treatment groups. At the end of the study, the effects of treatments in both groups were compared. The diagram of research design was described as follows:

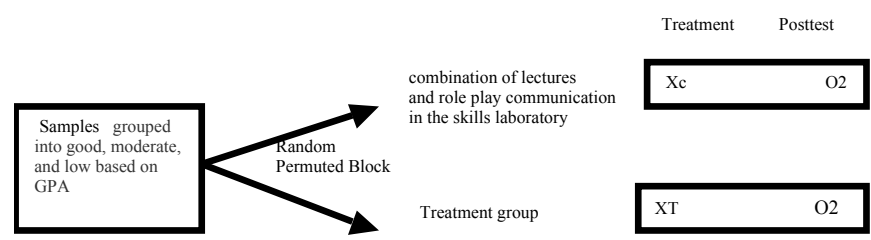

Fig 1. Diagram of research design: Posttest only control group design

At the end of the study, the total number of samples was 110 students. Impact of home visit as the family medicine learning method was assessed by comparing the level of student satisfaction towards the learning method of family medicine through questionnaires, scores of doctorpatient communication skills, and the test of the students ability to arrange the patient management plan with family medicine approach. When the data was retrieved and the overall study completed, additional home visits to educate patients and family (educational visit) was performed as moral responsibility and gratitude to patients and opportunity for control group to involve in home visit.

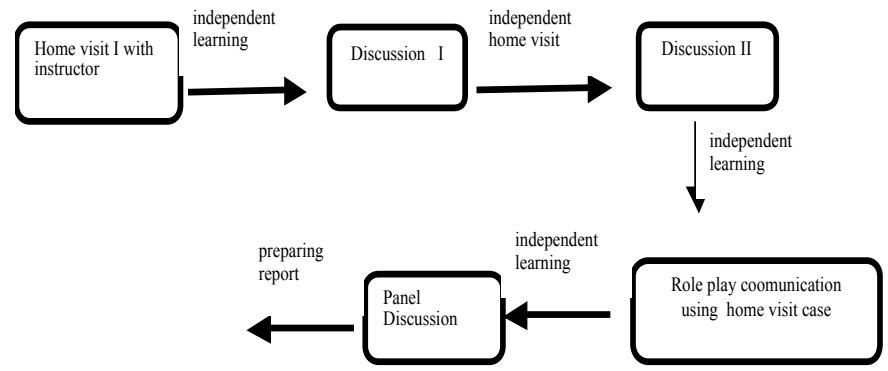

Figure 2. Model of home visit

\section{RESULTS}

\section{A. The difference level of student satisfaction in both study groups}

The difference of student satisfaction in both study groups was assess by using ordinal scale comparative test on two independent groups, the Mann-Whitney. Based on the Mann Whitney test, the test results listed in Table I.

TABLE I. THE DIFFERENCE LEVEL OF STUDENT SATISFACTION IN BOTH STUDY GROUPS

\begin{tabular}{|c|c|c|c|c|c|c|c|}
\hline & \multicolumn{3}{|c|}{} & \multicolumn{3}{c|}{$\begin{array}{c}\text { Group of combination of } \\
\text { lectures } \\
\text { and role play } \\
\begin{array}{c}\text { Aspect of } \\
\text { satisfaction }\end{array}\end{array}$} & \multicolumn{3}{|c|}{ Home visit group } & \multicolumn{3}{c|}{$\begin{array}{c}\text { Mommunication in the } \\
\text { skills laboratory }\end{array}$} & p \\
\cline { 2 - 9 } & $\mathbf{N}$ & $\begin{array}{c}\text { Median } \\
\text { (inter } \\
\text { quartile } \\
\text { range })\end{array}$ & $\begin{array}{c}\text { Min- } \\
\text { Max }\end{array}$ & N & $\begin{array}{c}\text { Median } \\
\text { (inter } \\
\text { quartile } \\
\text { range })\end{array}$ & $\begin{array}{c}\text { Min- } \\
\text { Max }\end{array}$ & \\
\hline $\begin{array}{c}\text { Achievement } \\
\text { of learning } \\
\text { objectives }\end{array}$ & 56 & $\begin{array}{c}4.00 \\
(0.75)\end{array}$ & $\begin{array}{c}(2.27- \\
5.00)\end{array}$ & 54 & $\begin{array}{c}3.36 \\
(0.73)\end{array}$ & $\begin{array}{c}(2.45- \\
4.45)\end{array}$ & 0.000 \\
\hline $\begin{array}{c}\text { Learning } \\
\text { process }\end{array}$ & 56 & $\begin{array}{c}3.92 \\
(1.00)\end{array}$ & $\begin{array}{c}(2.00- \\
5.00)\end{array}$ & 54 & $\begin{array}{c}2.83 \\
(1.17)\end{array}$ & $\begin{array}{c}(1.33- \\
4.33)\end{array}$ & 0.000 \\
\hline $\begin{array}{c}\text { Organizing of } \\
\text { learning } \\
\text { process }\end{array}$ & 56 & $\begin{array}{c}3.70 \\
(0.95)\end{array}$ & $\begin{array}{c}(1.60- \\
5.00)\end{array}$ & 54 & $\begin{array}{c}3.20 \\
(0.85)\end{array}$ & $\begin{array}{c}(2.00- \\
5.00)\end{array}$ & 0.031 \\
\hline $\begin{array}{c}\text { Benefits of } \\
\text { learning to } \\
\text { self- } \\
\text { development }\end{array}$ & 56 & $\begin{array}{c}4.22 \\
(1.08)\end{array}$ & $\begin{array}{c}(2.56- \\
5.00)\end{array}$ & 54 & $\begin{array}{c}3.22 \\
(0.94)\end{array}$ & $\begin{array}{c}(1.89- \\
4.89)\end{array}$ & 0.000 \\
\hline
\end{tabular}

\section{B. Communication skills of the patient-doctor through} family medicine approach in both study groups

Communication skills data was the interval scale, to compare the mean doctor patient communication skills with family medicine approach in both study groups was used unpaired $\mathrm{t}$ test. The test results listed in table II. 
TABLE II. BOTH STUDY GROUPS

\begin{tabular}{|c|c|c|c|c|c|}
\hline \multirow[t]{2}{*}{$\begin{array}{c}\text { Aspect of } \\
\text { communication }\end{array}$} & \multicolumn{2}{|c|}{ Home visit group } & \multicolumn{2}{|c|}{$\begin{array}{c}\text { Group of } \\
\text { combination of } \\
\text { lectures } \\
\text { and role play } \\
\text { communication } \\
\text { in the skills } \\
\text { laboratory }\end{array}$} & \multirow[t]{2}{*}{$\mathbf{P}$} \\
\hline & $\mathbf{N}$ & Mean \pm Sd & $\mathbf{N}$ & Mean \pm Sd & \\
\hline Builds a relationship & 56 & $20.67 \pm 3.04$ & 54 & $20.94 \pm 2.86$ & 0.638 \\
\hline Opens the discussion & 56 & $15.71 \pm 3.31$ & 54 & $15.39 \pm 3.47$ & 0.617 \\
\hline $\begin{array}{c}\text { Understands the } \\
\text { patient's perspective }\end{array}$ & 56 & $15.07 \pm 3.77$ & 54 & $14.77 \pm 4.36$ & 0.706 \\
\hline Shares information & 56 & $16.55 \pm 2.76$ & 54 & $16.50 \pm 3.19$ & 0.925 \\
\hline Reaches agreement & 56 & $31.73 \pm 5.31$ & 56 & $30.66 \pm 7.84$ & 0.409 \\
\hline Provides closure & 56 & $14.78 \pm 3.59$ & 56 & $14.92 \pm 4.10$ & 0.849 \\
\hline
\end{tabular}

\section{The ability to plan the patients management through family medicine approach in both study groups}

Based on the mean difference scores of communication skills using unpaired t test, it was found that there is no significant difference between the scores of communication skills in all aspects of the patient's physician communication on the method of home visits and combined lecture and lab exercises communication skills groups $(\mathrm{p}>0.05)$ as presented in table III.

TABLE III.

THE MEAN DIFFERENCE OF THE ABOLITY TO PLAN THE MANAGEMENT OF PATIENS WITH FAMILY MEDICINE APPROACH IN BOTH STUDY GROUPS

\begin{tabular}{|l|c|c|c|c|c|}
\hline \multirow{2}{*}{ Aspect of ability } & \multicolumn{2}{|c|}{ Home visit group } & \multicolumn{2}{|c|}{$\begin{array}{c}\text { Group of } \\
\text { combination of } \\
\text { lecture and role play } \\
\text { communication in } \\
\text { the skills laboratory }\end{array}$} & P \\
\cline { 2 - 6 } & N & Mean \pm Sd & N & Mean \pm Sd & \\
\hline $\begin{array}{l}\text { Ability to plan the } \\
\text { management of } \\
\text { patients with family } \\
\text { medicine approach }\end{array}$ & 56 & $73.58 \pm 1.03$ & 54 & $64.59 \pm 1.02$ & 0.000 \\
\hline
\end{tabular}

Based on qualitative data obtained all themes were relevant with home visit. Qualitative data obtained from open-ended questions on the student questionnaire, interviews with the instructor visits home, as well as interviews with the student group visits and student groups and lectures on communication skills training laboratory. Based on the analysis of quaitative data the themes that were relevant to the home visit are presented in the following table.

\section{DISCUSSION}

Home visit show promise in lowering medical costs while providing high-quality patient care. Policies such as the Independence at Home Demonstration showed cost savings with improved quality metrics, and it is clear that societal need for this model of care is increasing. Educating the upcoming generation of physicians to make or lead home visits and supporting physicians who provide this service will likely benefit both our patients and the health care system overall [9].

TABLE IV. THE THEMES THAT ARE RELEVANT TO HOME VISIT

\begin{tabular}{|c|l|}
\hline No & \multicolumn{1}{|c|}{ Themes } \\
\hline 1 & $\begin{array}{l}\text { Benefit of Home Visits method } \\
\text { Seeing reality, knowing the patient's perspective, honed empathy, } \\
\text { more applicable }\end{array}$ \\
\hline 2 & $\begin{array}{l}\text { Benefit of communication home visits method } \\
\text { Insights psychosocial communicating, application communication } \\
\text { techniques with real patients, train the courage and civility in } \\
\text { communication, recognize communication barriers, responding to } \\
\text { patients' needs for information, not monotonous }\end{array}$ \\
\hline 3 & $\begin{array}{l}\text { Benefits of learning experiences with home visits } \\
\text { Strengthening theory, motivation to learn, learning patient } \\
\text { management in a real case, self-evaluation, psychosocial health } \\
\text { insights, useful experience to become a doctor, practice } \\
\text { communication }\end{array}$ \\
\hline 4 & $\begin{array}{l}\text { Home visits feasibility asitive responses from students, faculty, and patients; costs and } \\
\text { Positive } \\
\text { resources quite affordable, adequate time. }\end{array}$ \\
\hline 5 & $\begin{array}{l}\text { Challenges in the implementation of home visits } \\
\text { Scheduling, preparation of implementation, program implementation, } \\
\text { faculty commitment, independence of student learning, program } \\
\text { placement in the curriculum, }\end{array}$ \\
\hline
\end{tabular}

The research was carried out in multisystem block and evidence- based medicine (block 16) consisting of 4 modules, where one of the modules, was family medicine. The study was to prepare and evaluate the impact of home visit as a learning method of family medicine. These activities include the preparation, implementation, and evaluation method of home visit. Student satisfaction towards family medicine teaching methods was measured by digging four aspects of satisfaction consist of the achievement of learning objectives, learning process, learning organization process, and benefits of learning to self-development.

Correct knowledge, positive attitude and true practice should have included setting the priority with special health care needs, learning by doing that that family-centered care and cultural competence work together, reaping the benefits of collaboration with caregivers with the core competence on psychosocial issues with an impact on morbidity, disability and mortality [10]. When carrying out home visits, there were many aspects of the communication of family medicine can be obtained such as training students sensitivity to identify psychosocial factors that affect health.. Good understanding of the psychosocial factors will assist students in making a diagnosis and developing a comprehensive management plan for the patient. Home visits will strengthen the student's theoretical basis because students will be motivated to read the theory according to the disease of visited patient. Qualitative data showed that home visit could hone student empathy and expose students to the reality of the health care which was received by the public. This will help the students to be wise in considering psychosocial factors when planning the management of patients. 
Home visit model in this research was developed by using the concept of experiential learning cycle, consisting of four steps, including Concrete Experiencing (CE), Reflective Observation (RO), Abstract conceptualization (AC), and Active Experimentation (AE) [11]. In this study, the first home visits and the independent visit were the implementation of $\mathrm{CE}$ and $\mathrm{RO}$ where students can engage more actively than learning by lecture method, thus potentially students have observed actively. In the first discussions, the students took steps $\mathrm{RO}$ and $\mathrm{AC}$ where students discussed the results of the home visit, reflected and got feedback from the instructors and other students in the group. The opportunity of reflection time and feedback was a good experience for students to evaluate what they have learned. AC step took place in which the students presented information analysis and management plan of patients that they have made. In the discussions activity, there also occurred a process of reflection and feedback, students would create a concept and described on conclusions about the experience and observations, this will lead to action in the future that will start a new cycle of experiences based on previous experience (AE).

This research shows that the level of student satisfaction in the intervention group was higher than the control group in all aspects of the satisfaction. The highest and the lowest of satisfaction of learning objectives achievement were awareness of the importance of good communication between doctor and patient and family (mean Likert scale: 4.44 ); and the ability to construct a family tree (mean Likert scale: 3.5), respectively. The highest satisfaction in the learning process was a learning method giving the real picture of health problems in the community (mean Likert scale: 4.25). One of the reasons that led to student satisfaction was the opportunity to meet in person and see the condition of the patient so that they get an overview of psychosocial factors affecting health. Students are also satisfied that they can practise communication skill with a real patient. This was consistent with research of Waddell (2000), in which students found a home visit was the process of learning from real-world experience [12].

The highest satisfaction to the benefits of learning for self-development in this study was the students feel a rewarding experience to be a doctor (mean Likert scale 4.47). The role of community-based training in family medicine and primary care provides a very positive outcome for the students' learning experience, not only provides a different disease settings, but also provide a complete context of the patient as well as the unique added value of learning that is different from a hospital-based education encompassing learning to communicate with the family and the opportunity to assess and manage the patient in a holistic manner ${ }^{13}$. Some publications mentioned a number of learning outcomes in the field related to the emotional aspect. Experience in the field of work provides a sense of satisfaction, being valued, being motivated, and confident. Positive emotions will develop the knowledge, clinical skills, and their learning skills. The students will develop their knowledge back to the real circumstance than just theoretical matter through experience in the field of work. They will learn to apply their skills prior to the real situations and to learn new skills. Early experience also makes them link theory and reality, being motivated by the introduction of the need to meet the characteristics of professional and to meet the lecturers who inspire, as well as providing self-development through the introduction of professional status and responsibilities in the future and recognize the differences in values and beliefs $[1,14]$. Home visit in Family medicine Residency indicated that the residents enjoyed the independence of doing housecalls on their own and found the experience worthwhile. One of the main challenges residents found with home visits was that of scheduling [15].

Some reasons for student dissatisfaction towards the achievement of learning objectives are the theory of family medicine obtained is less detailed, as well as material that is difficult to understand such as developing a family tree. Based on this, it can be concluded that the topics of family medicine considered difficult should be reinforced with other learning methods such as lectures or discussions. Lecture method is a method of learning that can be a main menu on difficult topics, an overview of a topic, different views on a subject, conclusions or the latest findings, and the reports of clinical or laboratory experience [16].

Several things that cause student dissatisfaction on organizing activity are the execution times spend was more than lectures on campus, remote location, difficult to find the patient's home, as well as the schedule of activities that did not fit the plan due to adjustment the visit occurance and instructor time. The research of Waddell also showed a similar thing in which the students and faculty stated that it took more time to do a home visit program, and the need for faculty to design a flexible time visit ${ }^{12}$. Although it had been tried to deliver family medicine learning well, there are several obstacles that could not be overcome. Study implementation of family medicine in the community setting still has many challenges, such as execution time, money, staff commitment, and support of the institution $[12,17]$; thus it is necessary to have a better preparation and to campaign more so that all parties involved can perform their respective functions.

Based on the mean scores of different communication skills test, it is found that there is no significant difference between the scores of the patientphysician communication skills in all aspects of communication in both study groups. It is different from the qualitative data which suggested that home visit has several positive impact including learning communication skills directly with real patients so that communication context is consistent with the community facts, bringing more empathy, and being able to recognize communication barriers. The two groups was used the same procedure sheet during communication training and also tested using that tool. Thus there is no real difference in terms of the communication training and exam preparation used by both groups. Although the students of home visit method had passed the learning 
process through real patients that is different from communication skills examination, still the students should study communication as well as communication skills test for the examination preparation.

Rees mentioned that one of the strongest motivations for studying communication is the availability of communication test, thus the students may learn communication in accordance with the carried out examination [18]. The assessment system has a large impact on student learning activities, such as its effect on students' learning approaches, how much time they spend on learning, how extensive they study learning programs, and whether they can understand the concept of the material being studied. Rees study also noted that the assessment of communication skills of students through the OSCE received criticism from students. The students assumed the OSCE does not reflect the actual student skills. Other reasons raised by the students were the OSCE is an artificial communication which does not describe the real communication, in addition to the OSCE, communication assessors only assess the communication process during a very short time. Students would rather be judged by who saw their communication in a variety of situations compared to assessor who only met them in 5-10 minutes and provide the assessment of communications [18].

Based on the mean scores of different test capabilities to plan the patients' management, it is found that the scores of the ability to plan the management of patients with a family medicine approach to the treatment group was significantly higher than the control group. The reason put forward to the difference of the scores shows that the test to plan patient's management is the application of family medicine. The ability to create a management plan requires the ability to identify problems and resources appropriate with the tested cases. In the process of student learning, the treatment groups were invited to learn problem identifications through real cases with information acquisition and direct observation. It is an experience that can serve as a model for managing other patients. Memorable experience will help students' comprehension and analytical skills [11].

According to the concept of experiential based learning proposed by David Kolb's, experiential learning starts from the actual experience that can be felt, seen, touched, and followed by an opportunity to reflect on the experience, accordingly the students will create a concept and describe conclusions about the experience and observations, so this will lead to the future actions with a new cycle of experiences based on previous experiences [11]. Qualitative data processing obtained five themes relevant to home visit as a learning method of family medicine. The themes were including the advantages of using home visit, communication advantages on home visit, the benefits of the learning experience on home visit, the home visit method is feasible, and challenges in the implementation of home visit.

Overall, the home visit method is accepted by students, faculty, and patients. Home visit provides benefits for students, patients, and home visit instructors. Home visit can be one method to complete learning system of family medicine at the preclinical. It is consistense with ramanayake research which showed that patients were willing to take part in undergraduate training without any reservation. These results are compatible with the previous studies done in the western world and data is not available form either Sri Lanka or other Asian countries [19]. Students, especially for students who have earned theory of diseases and will soon enter clinical phase of education. The home visit model created has been adjusted to the circumstances of medical education system in Indonesia and experienced several stages of validation, as well as efectivity tested. Therefore the home visit model is fairly to be developed and refined. The implementation of the home visit model can also be modified according to the characteristics and resources of local medical institutions.

Several limitation of this study such as only 3 experts were interviewed in the development of home visit model. If there were more experts interviewed, there would be other inputs which were not included in the home visit model. Contact between the two study groups was inevitable so that the research is not pure as the effects of treatment. Both groups can affect each other causing a bias in the study results. The researcher is familiar with both the students and the instructors interviewed so it is possible that the interviewed subjects tend to respond positively (Hawthorn effect).

According to the results of research and discussion that have been described above, there are several suggestions as follows:

1. Before being implemented, home visit need the preparation of handbooks, students, instructors, and home visit patient screening, as well as socialization and coordination to all parties concerned. In the implementation of home visit, it is necessary to consider the selection of a suitable block of related content, time, training time, and the burden of students learning, and the selection of instructors who have commitment, interest, and motivation to the program.

2. Lecturers who are involved in the home visit program need to increase the understanding of family medicine concept and commitment to the implementation of home visit programs. Lecturers are expected to increase selfmotivation to be actively involved in it, also give a positive impact for them to the behavior of health care professionals and family medicine approach. They are the agents of change for creating better physicians with respect to their roles both as a motivator and model for students.

3. The students are advised to increase the independence of learning since the benefits of home visit as the learning program will only be optimaly acquired if the student acts as the learning subject. The students are expected to utilize the experiences and concepts of learning obtained during the home visit activities for future selfdevelopment. 
4. Medical institutions should facilitate the implementation of the home visit program in order to give students the opportunity to learn based on community needs. It should be considered to form the department of family medicine or primary care to improve the ability of institutions to implementing learning of family medicine.

It needs more research to address the challenges encountered in the program implementation such as home visit scheduling, preparation of implementation, program implementation, faculty commitment, independence of student learning, placement program in the curriculum, as well as the student evaluation system needs to be developed further. The home visit method can be further cultivated as a learning method for a wide range of topics and stages of learning in medical school education.

\section{CONCLUSION}

In general it can be concluded that the model of home visits shows improve students satisfaction and students ability in planning patiens management with family medicine approach for preclinical students. Several themes related to home visits are the advantages of home visits model, the advantages of doctor-patient communication with home visits model, the benefits of the learning experiences through home visits, the feasibility of the home visit method, the challenges in the implementation of home visit.

\section{REFERENCES}

[1] Boelen C, Haq C, Hunt V, Rivo M, Shahady E, Improving Health Systems : The Contribution of Family Medicine. A guidebook Collaboration Project of WHO and Wonca. Singapore : Bestprint Printing Company. 2002

[2] Lubis F, Family medicine as back bones of health care system. Dokter Keluarga Sebagai Tulang Punggung dalam Sistem Pelayanan Kesehatan. Maj Kedokt Indon: 2008;58(2):27-34

[3] Konsil Kedokteran Indonesia (KKI), Indonesian Doctors Competency Standards. Standar Kompetensi Dokter Indonesia. Jakarta: Konsil Kedokteran Indonesia. 2012.

[4] Majumder AA, D'Souza U, Rahman S. Trends in medical education:challenges and directions for need-based reforms of medical training in South East Asia. Indian Journal of Medical Sciences; 2004;58(9):369-80.

[5] Roane MD, Teusink P, Wortham JA. Home visit in Geropsychiatry Fellowship Training, the Gerontologist, 2002;42(1):109-13.

[6] Burke M, Smith LG. Nurse-Practitioner- Led Home Care Curriculum for Third-Year Medical Students, The Mount Sinai Journal of Medicine; 2005;72(5):312-6.

[7] Gursoy ST, Ocek ZA, Ciceklioglu M, Aksu F, Soyer MT. Evaluation of an Educational Programme in Ege University, Turkey : Medical Student's Home Visits with Midwife Preceptors. j.midw;2008;24 : 226-37.

[8] Massachusetts General Hospital, Harvard Medical School. The role of palliative care in the home in medical education: report from a national consensus conference., Boston,Massachusetts, USA. (cited 2010 April 20). Available from: http://www.jbillings@partners.org

[9] Saerenji T, Jetti A, Peterson LE, shifting patern of Phycisian home visits, Journal of Primary Care \& Community Health 2016 , Vol. 7(2) 71-75.
[10] Pal R, Kumar R, Vidyasagar, Rustagi N, Mukherjee B, Sarbapalli D. Futue direction of family medicine training in India.Journal of family medicine and primary care; 2014;3 (4):294-99.

[11] Kolb DA, Boyatziz RE, Mainemelis C. Experiential Learning Theory: Previous Research and New Direction. Cleveland: Departemen of Organizational Behavior Whetherhead School of Management Case Western Reserve University. 1999.

[12] Waddell RF, Davidson RA. The Role of Community in Educating Medical Students: Initial Impressions from a New Program.Education for Health; 2000; 13 (1): 69-76.

[13] Mash B, Villiers M. Community-based training in Family Medicine-a different paradigm. Medical Education; 1999; 33:725-9.

[14] Dornan T. Experience based learning. Learning clinical medicine in workplace. Manchester : Universitaire Pers Maastricht. 2006

[15] Jakubavicz D, Srivasta A. Home visits in family medicine residency: Evaluation of 8 years of a training program. Canadian Family Physician; 2015;61:e189-95.

[16] Dent AJ, Harden RM. A Practical Guide for Medical Teachers. $3^{\text {rd }}$ Ed. US: Elsevier Limitted. 2009.

[17] Turner JL, Farquhar L, One Medical School's Effort to Ready the Workforce for the Future: Preparing Medical Students to Care for Populations Who Are Publicly Insured. Acad Med. 2008; 83:632638.

[18] Rees C, Sheard C, Davies S. the development of scale to measure medical students attitudes towards communications skills learning: the communication skills attitudes scale (CSAS). Medical Education; 2002:36:141-7.

[19] Ramanayake, Sumathipala, rajakaruna, ariapala. Patients' Attitudes Towards Medical Students in aTeaching Family Practice: A Sri Lankan Experience. Journal of Family Medicine and Primary Care. 2012;voll: issue 2: 122-6 